\title{
Analysis and Countermeasures of China's Network Marketing
}

\author{
Xiangyu Meng \& Yake Cao \\ College of Industrial and Commercial, Tianjin Polytechnic University \\ Tianjin 300387, China \\ E-mail: aryu0929@163.com
}

\begin{abstract}
The development of network marketing go with the progress of Internet, it's an inevitable trend that network marketing instead of traditional marketing. The fact has wake the enterprises managers up to the circs, at the same time, more and more enterprise have made the decision to carry network marketing into execution. However, the imbalance of economic and the characteristics of network marketing, as a result lead to many problems. Therefore, we could summarize following problems, and give some countermeasures.
\end{abstract}

Keywords: Network marketing, Net security, The third logistics

\section{Introduction}

With the extensive use of computer technology and improvement of network technology, the informatization has been rapid development in our country. Network gets closer to our daily lives from the original web-based information browsing to variety network Mall building. We could command the real-time information and feel the unlimited fun of online shopping.

Network marketing is an integral part of the enterprise' overall marketing strategy, and the process to achieve the overall objectives, as various activities which is the basic means to create an online business environment. (Feng, 2002). Network marketing is the production of marketing practice, modern information, communication technology and computer network technology, which is the basic of information, the medium and means of computer net.

\section{Analysis of Networking Status QUO in China}

China's Network marketing started-up rather late, it started to try until 1996 in the enterprise, in recent years, with the rapid development of network technology, China's network marketing also flourishes. To promote the development of network marketing, China's created a good social and political environment. By the end of 1993, it began implementing the "three gold" project and the project started the domestic information technology prelude. In 1996, based on the Information-based joint meeting of the national economy, the Government established the Council Informationization Leading Group, listed the enterprise information technology, the e-commerce and the e-finance as the three key tasks, put forward the "push forward the informationization of the national economy, enterprise information is the foundation, financial computerizing is the guarantee, e-commerce is the core," as guiding ideology, encouraged Network Marketing pilot, strengthened the network of policy research, participated in international networks of dialogue. In 1999, China promulgated a new contract law of network marketing which has developed a number of norms, even though not yet ripe, but always step in a big step, they enable enterprises to carry out the activities of network marketing has some legal basis. In the first half of 2000, the Ministry of Information Industry Organization drafted a "national framework for the development of electronic commerce." Despite the great support of our government , but our network infrastructure were behind the developed countries overall, as well as the Internet technologies and the corresponding system was not perfect, it resulted in China's online marketing still had a large gap compared with developed countries, the level of integration is still relatively low, still at the initial stage.

According to the analysis about large and medium-sized enterprises, the mainly problems in the development of network marketing in the following aspects:

First, infrastructure of network drop behind the need of network marketing, there is a lack of hardware. Although in China, computers have been widely used in recent years, the rate of Internet users growth soon. However, it is imbalances that young people are the mainly users. There is a big inequality between east and west, county and city. There was a adding of Internet users about 91 million last year, of which more than 68.6 percent were youngster. 
Youngster have the ability to accept new things, with the popularization of higher education, more and more youngster have the opportunities to receive continuing education, thereby increasing the likelihood to contact with network and computer. The imbalances of east-west economic resulting in the fact that the rate of the eastern computer ownership was lower than the western region.

Second, the protective procedures are incomplete, and network marketing develops difficultly. The protective procedures include that the laws and regulations safeguard against the inaccurate contents related to network marketing and the construction of firewall of computer network itself. Our current laws do not match the reality of network marketing. The rights and interests of consumers, the legal status of third-party certification, the punishments of cybercrime and so on involved in the network marketing are not clearly defined in the law of our country. Now the offensive capabilities of hackers are getting stronger and stronger, even if the specialized IT team is also very difficult to cope with them, so this threats security of the important link of network marketing-online payment and online information of customer. These will inevitably affect the enthusiasm that enterprises or individuals engage in network marketing.

Third, the third-party logistics does not build perfectly. (Lin, 2005) For network marketing, the third-party logistics plays a key role in distribution of goods. In general, the thing to attract customers' eyeball in network marketing is the price advantage, and that is also the most principal advantage. If the costs of logistics and distribution are too high, it will reduce the price superiority of the network marketing or even offset it. The most important advantage of internet marketing-price advantage disappeared. In addition, if third-party logistics and distribution can not be guaranteed, it is difficult to ensure the timely arrival of goods to the hands of customers. Regarding some staple commodities or batch products, if such a situation happens, it will lead to very serious consequences. Therefore, the third-party logistics not only need ensure accurate and prompt distribution of commodities, but also should reduce greatly the loss in the allocation of commodity to ensure the price advantage of network marketing. At present, Chinese development of the third-party logistics is not very perfect, and can not be mentioned with abroad famous logistics companies such as Federal Express in the same breath, and under the impact of foreign perfect logistics companies, it is difficult for Chinese third-party logistics to build their own brands.

Fourth, the lack of the necessary talent of network marketing. Compared with the traditional mode of marketing, network marketing professionals should be required to have the computer technology and internet marketing knowledge, and these two aspects are indispensable, not an independent division of labor. This is because as network marketing involves to the construction, maintenance and updating of site, non-specialized computer personnel may not be able to complete the corresponding work; while general computer professionals are unable to achieve professional qualities which the traditional marketing models required. Thus, the specialized talent of network marketing seems particularly important.

Fifth, the shortcomings of the concepts and understanding(Kong, 2007, p. 9-10). Although network marketing is no longer a new thing, the current initial stage of domestic network marketing determines that the development of network marketing is bound to take a lot of detours, even the existence of circuitous. The leadership of companies have recognized the inevitable trend of the implementation of network marketing, and many companies have begun the implementation of online marketing, but they are not satisfied with the economic profit that network marketing brought about in a short period, thus give up the implementation of network marketing, which is the result of inadequate reorganization on network marketing, then led the network marketing of the majority of enterprises to the final form of a static page fruitlessly.

\section{Suggestions and Countermeasures}

In this regard, the business leaders who will prepare for the implementation of network marketing have to understand clearly network marketing. In a very short period it can not bring economic benefits for enterprises, and the whole implementation is a scratch of a fully new process. Only do a good job of long-term plan to marketing, can enterprise do a good job of network marketing and eventually it may became the main mode of the marketing of corporate and bring endless space of profits for the enterprise. Network marketing is the long war of "Eight years of the Anti-Japanese War", also a tough battle.

With the development of computer technology and network technology, network marketing is developed. Therefore, the computer technology and network technology problems also baffled the further development of network marketing. Through the above analysis, we can realize clearly, the hard problems that network marketing facing need to be solved by us. In view of the above problems, put forward following suggestions.

Firstly, infrastructure of network marketing need to be strengthen, effort to narrow the disparities among east and west, as well as urban and rural. In view of economic development imbalance between east and west, to fundamentally solve the problem of east-west gap in the network infrastructure issues, but also proceed with the economic development disparities between east and west. As a country, we must step up the economic construction devotion into the western 
region. Infrastructure construction will be also progress and development going with the development of economic construction, however, there isn't no work to be done recently, we must root the network marketing idea in the enterprises, when some imperfections being in the construction of infrastructure, engaged in network marketing for the future lay the ideological foundation.

Compared to the western region, in many rural parts of China has achieved a moderately prosperous level, these rural homes where the computer penetration rate is not too high, but they are not paid network infrastructure building, just from the level of education and ideologically not realize that benefits network offer to them. Therefore, in terms of this part of rural families to allow them to receive a computer, acceptance network, network marketing to accept only a matter of time, as long as the popularity of computer knowledge, strengthen the construction of computer networks in rural investment, I believe that this gap between urban and rural areas will ultimately be resolved.

Secondly, improve the marketing network to the required safety building, including network security, legal security and credit security. Network security is the means needed to complete the online consumer transaction security, enterprises should protect their customer data is not stolen; when customers and enterprises to carry out online communication, it is necessary to ensure that their calls will not be a third party to steal content; online payment process to ensure that bank account number and password is not stolen. In this regard, to strengthen the technical maintenance of the network, including physical security, firewall security and network topology security. For network marketing business, it is necessary to the formation of a skilled team of IT, not only able to complete day-to-day network maintenance enterprises, and to build a secure network system, the formation and hackers opposing network security team to deal with from all sides network attacks, in order to ensure the smooth progress of network marketing.

Legal security refers to the different network security hazards arising from the conduct of Internet users to give a certain degree of legal sanctions. At present, China's laws for network security standards are not perfect, the network of fraud, theft of credit card password and other crimes, there is no specific sanctions, which also led to the current Internet crime and online fraud become increasingly rampant activities of the main reasons. The laws of State and regulations to strengthen the norms, and the expansion of cyber-crime conviction of space, and ensure network security, network marketing for the rapid development of legal protection.

Credit security, the so-called security is a means of credit in the process of network transactions, both basic information and transaction information from third-party access, and in order to ensure the successful completion of the transaction, the two sides should adhere to the provisions of the transaction. Credit security on the one hand, on an individual basis as the main course of personal credit problems, such as online transaction agreement will be as a child's play, I would like to sign on the sign, even if not required to comply with the signing, with breach of contract on the breach of contract; registered members process false information, false name and false ID number, etc., to disrupt the network order. In the network world, is there some people, doing nothing will be happy as a means of seeking a means of deception. On the other hand, enterprises do not pay attention to the protection of customer information, free leaked, leading to customer information on the network can transmit, which is bound to give troubled enterprises. Credit security, not only in need of legal restraints and, more importantly, moral constraints, only a profound understanding of the importance of credit security before they can provide for network marketing piece of pure land.

Third, enhance the development of the third logistics, ensure network marketing consignment favoring. Consignment is not only the finally step but also the most important tache which affect the quality, safety and betimes of commodity during the whole network marketing. The government should hearten the development of consignment by way of the macroeconomic control .On the one hand, debase the cost of fuel and repair, the other hand, afford some favorable prices to insure the development of the third logistics.

Fourth, constitute the scheme of network marketing talents; intensify the cooperation with colleges and scientific search departments. The requirement of professional network marketing talents is increasing with the development of network marketing .Enterprises should actively fetch in network marketing talents, at the same time, colleges should increase inputs in fostering professional. Colleges should tune the setting of subjects in order to give support to the network marketing.

Fifth, improve the cognition, envisage the orderliness of network marketing, and change the traditional thinking about profit. There is a big difference between network marketing and traditional marketing. Traditional marketing can make a definitude strategic target. So, it could create profit during a short time. But the particularity of network marketing make the result that network marketing can't create proceeds. It needs a long time to spread a company's web site. Therefore, it will cost two or three years that network marketing make function.(He,2000,p100)

Through analysis, we can clearly find the status and problems of network marketing. Network marketing is the upgrading of the traditional marketing; it can not be divorced from the traditional network marketing. The thinking and methods of traditional marketing is still applicable on the network marketing. Network marketing is the development of traditional marketing; enterprises should understand the necessity of network marketing and make a long-term preparation. 


\section{References}

Feng, Xingjian. (2002). The Basis and Practice of Network Marketing. Beijing: Tsinghua University Press.

He, Cihao \& Luo, Suihong. (2000). The Constraints and Countermeasures of China's network marketing. Economic Management of Business.

Kong, Pengju \& Zhang, Yi. (2007). The Status \& Obstacles \& Countermeasures of Network Marketing in China. Inner Mongolia Science Technology \& Economy, 137(7):9-10.

Lin, Huidan. (2005).The Third Logistics. Shanghai: Shufe University press.

Principles of Marketing. America. Prentice-Hall International. Ine.

The Investigation Report of Internet Development in China. (2008). Beijing: Internet Network Information Center in China. 